\title{
Nimotuzumab in Advanced Cervical Cancer: Safety and Efficacy Profile
}

\author{
Raiza Ruiz Lorente, Sayly Alfonso, Yamilka Sanchez, Carmen Elena Viada, Ramón Ortiz, Mayelin Tro- \\ che, Meylan Cepeda, Ana Rosa Vals, Leticia Cabrera, Annia Gorte, Delmis Maira Batista, Milagros \\ Domenech, Jessica Garcia Viamontes, Conrado Ramos Mico and Mayra Ramos Suzarte*
}

Center of Molecular Immunology, Atabey, Havana, Cuba

*Corresponding author: Mayra Ramos Suzarte, Center of Molecular Immunology, 216 \& 15 Street, Atabey, Havana, Cuba

\begin{abstract}
The EGF receptor is over expressed in tumors of epithelial origin and is associated with a poor prognosis of the disease. An Expanded Clinical Access Program was carried out, in which patients with cervical uterine cancer in advanced stages of the disease without another therapeutic alternative were treated with nimotuzumab, anti-epidermal growth factor receptor humanized monoclonal antibody to evaluate the safety and efficacy of this therapy. Seventy-five patients with confirmed histological diagnosis of advanced cervical cancer were included, with previous onco-specific treatments (surgery, radiotherapy or radiochemotherapy), with ECOG at the inclusion $\leq 3$ and life expectancy of more than three months. The mAb was administered in two stages: The induction stage with weekly administration, once a week in a dose of $200 \mathrm{mg}$ intravenously; for twelve weeks and the second or maintenance stage with the same dose but every 14 days, until unmanageable toxicity or the decision of the patients. The therapy was well tolerated with an acceptable safety profile, not exceeding $2 \%$ the severe adverse events related to nimotuzumab treatment. The median overall survival exceeded the expectation by arriving at 23.5 months. We suggest follow up to a clinical trial in more early stage of the disease to combine nimotuzumab with chemo-radiotherapy.
\end{abstract}

\section{Keywords}

Nimotuzumab, Cervical cancer, Advanced, General survival Safety

\section{Introduction}

Cervical cancer, despite being one of the preventable locations with simple diagnostic methods such as the Papanicolaou test and more recently with the detection of DNA (or RNA) of HPV virus types 16 and 18 in cervical cells [1], it is maintained with an overall incidence of 528,000 cases in 2012 with an annual increase of 266,000 new cases. Eighty-five percent of the cases are diagnosed in developing countries [2]. Approximately 12,990 new cases were diagnosed in the US in 2016 and 4120 women died of this cause. Although the disease has decreased due to screening and preventive vaccination programs against the most oncogenic subtypes 16 and 18 of Human Papillomavirus (HPV), the incidence remains high in women of Latin, black and Asian origin [3].

According to PAHO in Latin America and the Caribbean, cervical cancer mortality is 3 times higher than in the US and Canada, with around 92,132 cases and 37,640 deaths annually, reporting a direct association with socioeconomic development and access to Health programs [4]. In Cuba, according to the Statistical Yearbook of Health, it is the $5^{\text {th }}$ cause of mortality with 512 cases in 2016, with the highest number of deaths between 40 and 59-years-old [5-7].

It is estimated that $35 \%$ of cervical tumors are diagnosed as a locally advanced disease (stage Ib2-IIIb according to the staging system of the International Federation of Gynecology and Obstetrics (FIGO)) with an estimated survival rate of 5 years in $60 \%$ of the cases, using the standard treatments of concurrent chemoradiotherapy based on platinum [8-10]. One percent

Citation: Lorente RR, Alfonso S, Sanchez Y, Viada C, Ortiz R, Ortiz CEVR, Troche M, et al. (2019) Nimotuzumab in Advanced Cervical Cancer: Safety and Efficacy Profile. Int J Oncol Res 2:016. doi. org/10.23937/2643-4563/1710016

Accepted: July 27, 2019; Published: July 29, 2019

Copyright: (c) 2019 Lorente RR, et al. This is an open-access article distributed under the terms of the Creative Commons Attribution License, which permits unrestricted use, distribution, and reproduction in any medium, provided the original author and source are credited. 
of these patients become as persistence (around 20\%) or in relapse of the disease, where the platinum-based chemotherapy (Carboplatin and Cisplatin), the Taxans (Paclitaxel and Docetaxel), the Gemcitabine and the Topotecan are presented as the main therapeutic option [11].

Passive immunotherapy associated with the epidermal growth factor receptor (EGF R), using monoclonal antibodies (MAbs) have been demonstrate the specificity recognition of the receptor by the antibody and the inhibition of the ligands binding to it, evidencing an inhibitory effect of the mytogenic stimulation of the malignant cells [12].

In immune-histochemistry evaluations, it was found that over expression of EGF-R in squamous cells carcinoma of the uterine cervix has a direct relationship with the rate of tumor growth [13]. This receptor is associated with the poor prognosis of the disease because participate in the processes of proliferation of malignant cells, the invasiveness of healthy tissues, in addition to favoring the mechanisms of angiogenesis and inhibiting apoptosis [14].

The humanized Mab nimotuzumab (IgG1) recognizes the domain III of the EGF-R with a $10^{-9} \mathrm{~mol} / \mathrm{L}$ constant of dissociation (considered as intermedia in relation to those reported for this type of antibodies) [15]. It avoids the interaction of EGF, (and other ligands) to its receptor and the consequent signals transduction to the nucleus, which favors blocking all its activating functions [15].

Safety and efficacy of nimotuzumab as a single agent or in combination with radio and chemotherapy in tumors from head and neck, glioma, esophagus, pancreas and more recently in advanced persistent or recurrent cervical cancer has been reported; showing an excellent safety profile, control of antitumor activity and improvement in survival [16-18].

Through the present, it is evaluated the safety and efficacy of nimotuzumab in patients with cervical cancer in advanced disease (relapse, tumor persistence or metastatic and refractory to previous oncospecific treatments), without therapeutic alternatives at the time of being included in the study.

\section{Methods}

A multicenter, prospective Expanded Clinical Access Program was performed. It was approved by the Institutional Ethics Committees for Clinical Research (six Cubans hospitals) and officially communicated to the Cuban Drug Regulatory Agency (CECMED).

Seventy-five patients were included since 2008 to 2010. All of them fulfilled the follow inclusion criteria: Informed consent to participate in the research duly signed, confirmed cito-histological diagnosis of cervical cancer, persistent or relapsing or in advanced disease without therapeutic alternative, previously received oncospecific treatment (surgical, radiotherapy, chemotherapy or the combination of these), ECOG $\leq 3$, and normal functional parameters of clinical laboratory. The exclusion criteria was those patients who were receiving another investigational product or nimotuzumab, pregnant or breastfeeding, who refused to sign the informed consent and with ECOG $>3$.

\section{Treatment}

Nimotuzumab was administered in a dose of 200 $\mathrm{mg}$ intravenously; once a week, for 12 weeks in the induction stage and $200 \mathrm{mg}$ every 14 days until the onset of unmanageable toxicity or worsening of the general condition of the patient above 3 according to the ECOG scale. The safety and efficacy (concerning to survival time) associated with the treatment with the MAb was evaluated. Demographic and toxicity parameter were tabulated with descriptive statistics and was reported as absolute and relative frequency.

\section{Toxicity evaluation}

For the toxicity analysis, the adverse events were classified according to the table of Common Toxicity Criteria (CTC version 3.0 of the National Cancer Institute of USA). Tenor more times are considered as more frequently and as related to the ACM treatment all those had some causality relation with it (possible, probable and definite).

\section{Evaluation of effectiveness}

The main efficacy variable was the overall survival time (OS), measured from the date of initiation of treatment with the MAb to the date of death of the patient (or last life date news), using the Kaplan-Meier nonpara-

Table 1: Demographic characteristics of patients.

\begin{tabular}{|l|l|l|}
\hline Variables & Patients & \% \\
\cline { 2 - 3 } & $(\mathbf{n = 7 5 )}$ & \\
\hline Age (years) & $65(29-77)$ & \\
\hline Histological & & \\
\hline -Epidermal Carcinoma & 44 & 58.6 \\
\hline -Adenocarcinoma & 6 & 8.0 \\
\hline -Others & 25 & 33.3 \\
\hline ECOG & & \\
\hline 0 & 19 & 25.3 \\
\hline 1 & 37 & 49.3 \\
\hline 2 & 3 & 4.0 \\
\hline 3 & 5 & 6.7 \\
\hline Not available & 11 & 14.7 \\
\hline Previous Treatment & & \\
\hline CRT & 38 & 50.7 \\
\hline RT & 12 & 16.0 \\
\hline CT & 3 & 4.0 \\
\hline Not previous treatment & $12^{*}$ & 16.0 \\
\hline & & \\
\hline
\end{tabular}


metric estimator for the variances and the confidence intervals of these. Survival curves were compared using the Log-Rank test considering a significance level $\alpha$ $=0.05$ and a bilateral test. This variable was analyzed by Intention to Treat (ITT) and by compliance with the protocol (PP), considering for the first all patients included in the study and for the latter those who received at least 6 doses of nimotuzumab.

\section{Results and Discussion}

Seventy-five patients were included from January 2008 to May 2010, with follow-up until December 2018, the clinical, pathological and therapeutic characteristics are summarized in Table 1. The average age was 65 years (range of 29-77), the most frequent histological type diagnosed was squamous carcinoma in $58.6 \%$ of the patients and ECOG 1 predominated in $49.3 \%$.

More than $50 \%$ of patients had locally advanced disease at diagnosis, however, at the inclusion in the clinical program were in advanced, persistence or relapse disease. Most of the patients received previous oncospecific treatment: $50.7 \%$ received the combination of external radiotherapy with $\mathrm{Co} 60$ in four pelvic fields for a total dose of $50.4 \mathrm{~Gy}$ with concurrent cisplatin chemotherapy at a weekly dose of $40 \mathrm{mg} / \mathrm{m}^{2}$ of body surface for 5 weeks, followed by Brachytherapy of high dose rate with $600 \mathrm{cGy} / \mathrm{session}$, four times. Twelve patients had not received previous oncospecific treatment because they were in very advanced clinical stages and refuse chemotherapy.

\section{Toxicity}

Table 2 shows the safety profile in the clinical study. Adverse events (AE) that appeared during the treatment in all of the included patients were evaluated as causal relationship. In 53 patients, 354 events were reported, out of 75 patients, treated 53 patients manifested some $\mathrm{AE}$ and only 18 were classified as related to nimotuzumab (24\%), the most frequent reported SAEs were related to the administration of the MAb.

Although the pain was the most frequent reported associated with the administration of the MAb, this could be related to the advanced stage of the disease, since the intravenous administration require stay at the hospital for observation, at least two hours, however, this product was well tolerated and administered for prolonged periods in patients with long survival. Any new AE was reported for nimotuzumab [19-21]

The NCCN for cervical cancer in 2018 recommends as category $2 \mathrm{~B}$ the use of Bevacizumab mAb as monotherapy [22] and, more recently, pembrolizumab [23,24], however, grade III adverse reactions such as hypertension, thromboembolic phenomena and gastrointestinal fistula are described [22]. Taking into account that the patients evaluated in this study received nimotuzumab as a second line therapy (or more) for their recurrent or metastatic disease and the administration was prolonged, even after progression in the monotherapy way, the safety profile is superior to other antibodies and are better tolerated.

In a prospective, phase II pilot study conducted from 2010 to 2015 in patients with locally advanced cervical carcinoma at Nanhai District University Hospital in the People's Republic of China, which included 80 patients treated with nimotuzumab concomitant with chemotherapy. Fourteen percent of the patients reported complete response, $88 \%$ control of the disease and $74 \%$ stable, showing a safety profile similar to that of the present study [17]. Another phase II study was reported by Cetina and cols. in 2015, conducted at the National Institute of Mexican Cancerology (INCAM) combining

Table 2: Nimotuzumab toxicity. General profile of toxicity in the clinical study by patients and adverse events.

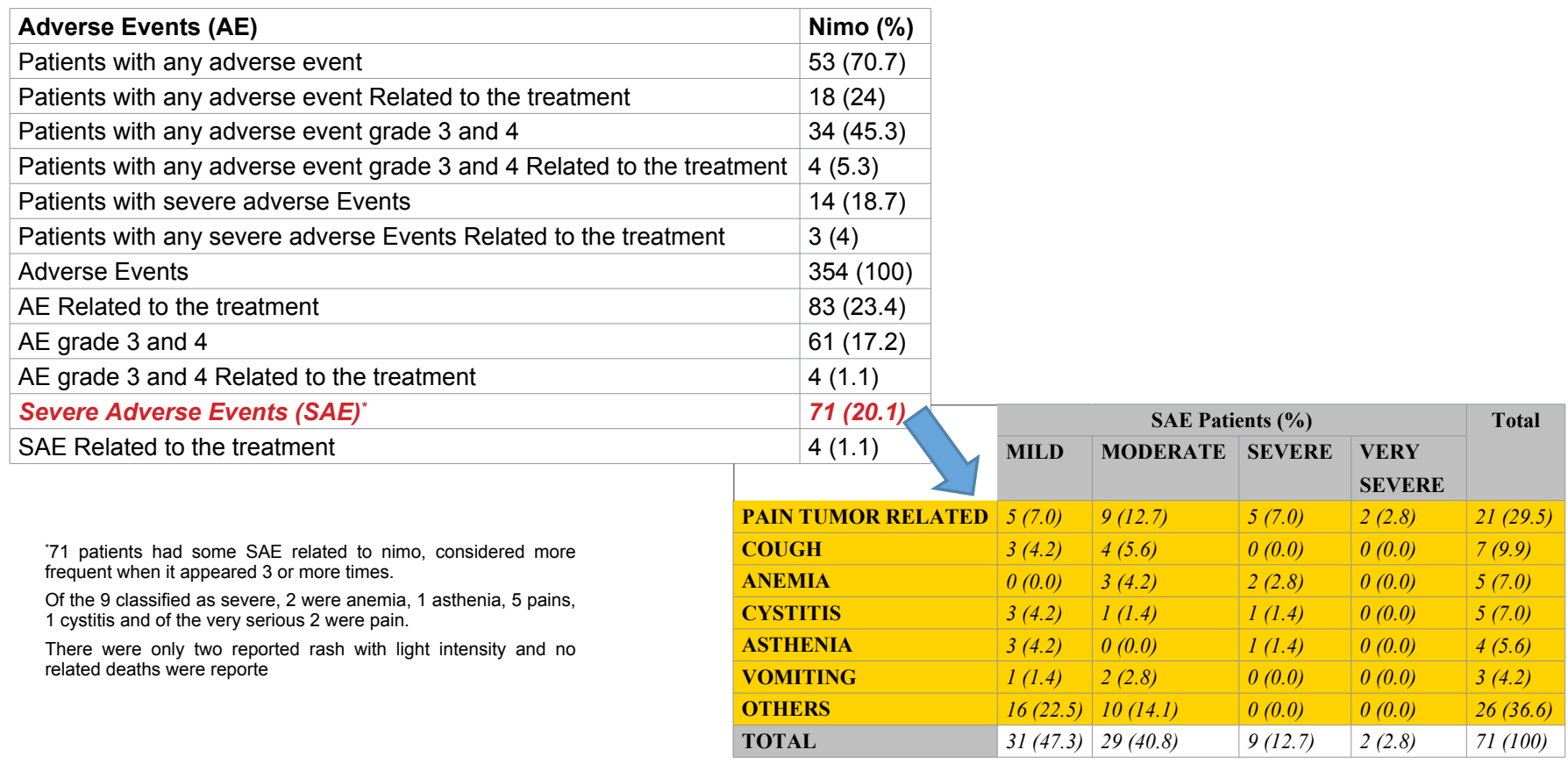


cisplatin/gemcitabine chemotherapy with nimotuzum$a b$ in 17 patients with persistent or recurrent cervical cancer after several lines of chemotherapy treatment. The induction phase of the treatment with the MAb for 4 weeks concurrent with the chemotherapy, and the maintenance every 14 days until tolerability of the patient. The treatment was well tolerated with mild or moderate toxicity, both in the induction and maintenance stages, achieving a stabilization of the disease in $35 \%$ of the patients included in the study [18]. Independently of the fact that in the present study the patients did not receive a concomitant oncospecific therapy such as those mentioned above, which could increase the toxicity of nimotuzumab, they were in a more advanced stage of the disease and even then the treatment was very well tolerated (Table 2).

\section{Efficacy evaluation}

Efficacy was evaluate in terms of overall survival, analyzed by intent to treat (ITT) and per protocol (PP) (Figure 1). Others factors that could have an impact on survival were also take into account for this analysis: first, the histological type (Figure 2); second, the
ECOG at the time of inclusion (Figure 3). The behavior regarding previous therapies was consider as the third factor, resulting that untreated patients demonstrated a higher survival. This last could be related to the expression of EGFR in the untreated tumors, since the previously therapy could have a modification of the over expression on the tumor surface, as has been previously reported by several authors, [25-28] for this reason it is now essential to characterize the tumor once again when starting a biological therapy (Figure 4).

In the ITT survival analysis (OS) a median survival of inclusion was obtained at 23.5 month study, with a 4-year survival rate of $40.7 \%$. It was higher than that reported in the GOG 240 study ( EC phase III randomized study of Bevacizumab (anti-angiogenic MAb) concomitant with chemotherapy with cisplatin/paclitaxel and topotecan/paclitaxel in which a significant OS of 17 months vs. 13.3 months was obtained $(p=0.004))$ [29]. Those patients who received at least 6 doses of nimotuzumab (PP) did reach 31.1 months as median survival.

In the study conducted by Cetina and cols; where nimotuzumab treatment with concurrent chemotherapy with cisplatin and gemcitabine was applied to patients

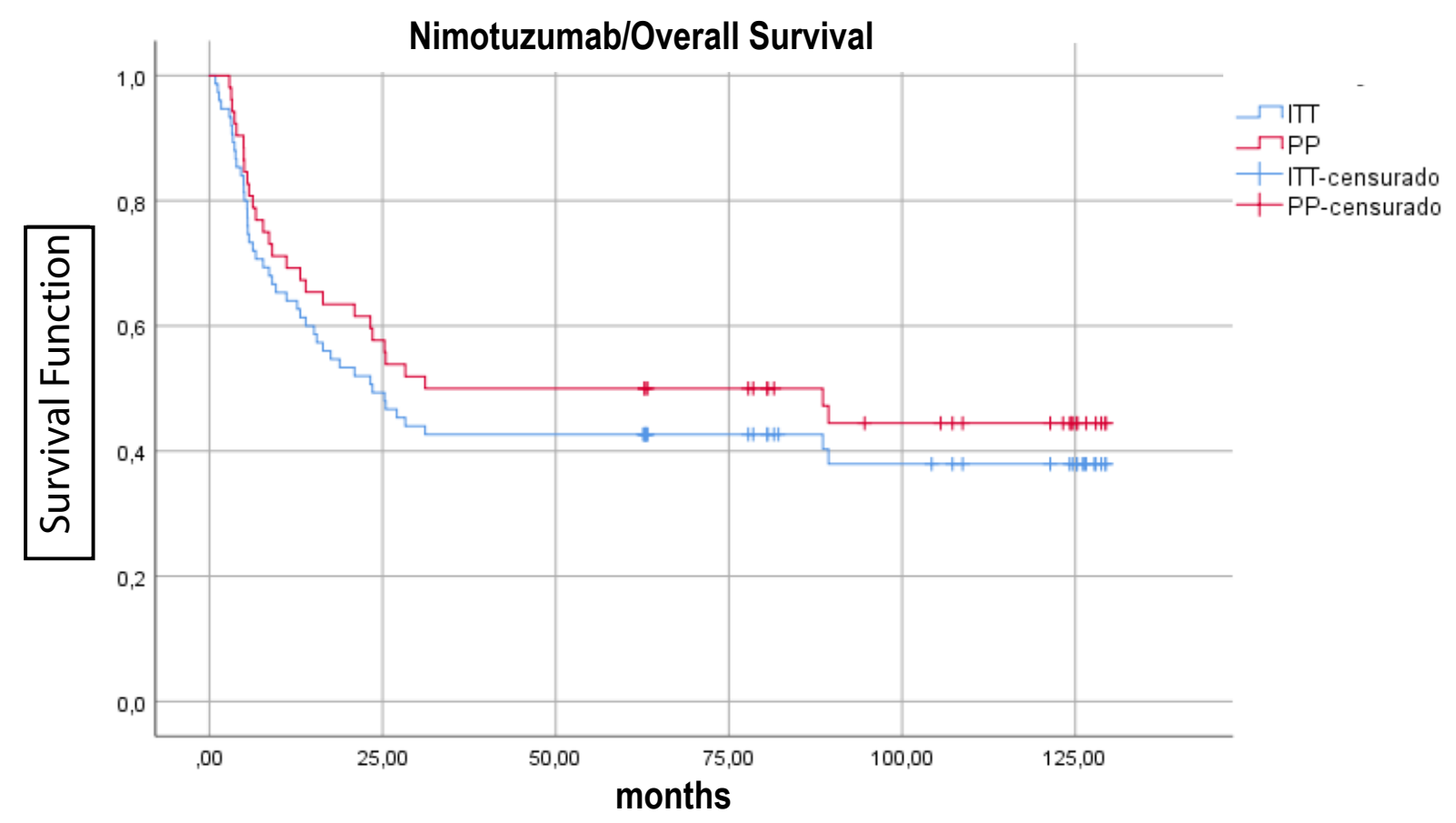

\begin{tabular}{|l|l|l|l|l|l|l|l|l|}
\hline Patients & \multirow{2}{*}{$\begin{array}{l}\text { Mean } \\
\text { (months) }\end{array}$} & \multirow{2}{*}{$\begin{array}{l}\text { Median } \\
\text { (months) }\end{array}$} & \multicolumn{6}{|l|}{ Survival rate (months) \% } \\
\cline { 3 - 9 } & & $\mathbf{6}$ & $\mathbf{1 2}$ & $\mathbf{1 8}$ & $\mathbf{2 4}$ & $\mathbf{3 6}$ & $\mathbf{4 8}$ \\
\hline $\mathrm{ITT}$ & 59.46 & $\mathbf{2 3 . 5}$ & 73.3 & 64.0 & 54.7 & 49.3 & 42.7 & 40.7 \\
\hline $\mathrm{PP}$ & $(46.3-72.5)$ & $(12.3-34.7)$ & & & & & & \\
$\mathrm{N}=52$ & $\begin{array}{l}68.4 \\
(52.7-84.1)\end{array}$ & $\begin{array}{l}\mathbf{3 1 . 1} \\
(0.0-108.0)\end{array}$ & 80.8 & 69.2 & 63.5 & 55.8 & 50 & 50 \\
\hline
\end{tabular}

Figure 1: Global Survival of the study. 
with recurrent or persistent cervical cancer; the OS was 299 days (9.9 months) [18]. While in another similar investigation by Chen and cols. applied nimotuzumab with chemotherapy in similar doses and schemes at present, OS was obtained of 11.96 months (8.11-23.95) with an IC of 95\% [17].

Recently Lu, et al. reported a clinical trial in 28 patients previous diagnosed of locally advanced cervical cancer. Neoadjuvant treatment of chemotherapy with concurrent platinum salts was applied with intensity modulated radiotherapy (IMRT) together with weekly nimotuzumab for 5-6 weeks was the treatment proposed; obtaining a complete response in 8 patients and a partial response in 20 . It was possible to perform a hysterectomy with lymphadenectomy in 22 cases, demonstrating moderate over expression of EGFR moderately in $28.6 \%$ and high in $50 \%$ of cases [30].

In this combination modality of nimotuzumab with the onco-specific treatments of chemotherapy and radiotherapy before surgery, they reported a follow-up of 22 months with a range of 5 to 39 months, a survival of $90.0 \%[30]$.

The present report shows the results of nimotuzumab as monotherapy in patients with persistent, recurrent or metastatic cervical cancer, yielding a median
OS of 27 months. The 48-month survival rate indicates that the probability of patients being alive at that time is upper than $40.0 \%$ for ITT and $50.0 \%$ for those who at least received the induction dose with nimotuzumab for 6 weeks. (Figure 1)

Some factors were taken into account to identify the populations that could benefit from this treatment. In this case, Figure 2 shows the histological type of the original tumor could be related to the advantages of OS, being the patients with epidermal carcinoma, the most benefited in relation to adenocarcinomas (ADC) and other tumors of epithelial origin that were included in the study. This could be directly relate to over expression of EGFR in squamous tumors due to its epithelial origin, much higher than ADCs of glandular origin [2428,30].

In the evaluation of the general state of the patients at the moment of the inclusion, it influenced not only the extension of the disease, but also the sequels of the previously surgical procedures, chemo and radiotherapeutics treatments, which were reported as functional or organic, in different degrees before entering the study. Although all were included in advanced disease and without therapeutic alternatives, those that presented a better performance status (0-1) had a superior

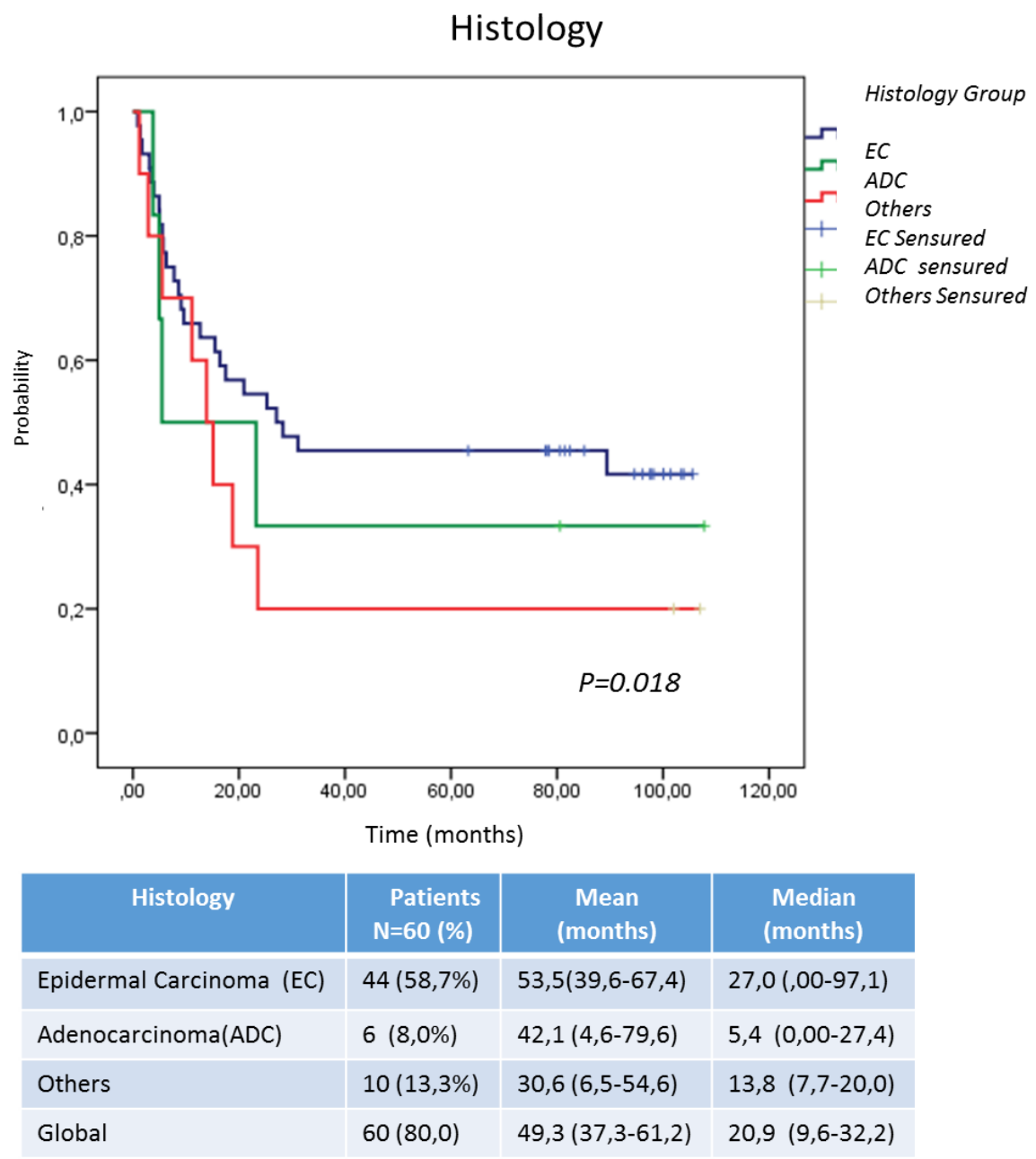

Figure 2: Survival according to histological type at diagnosis. 


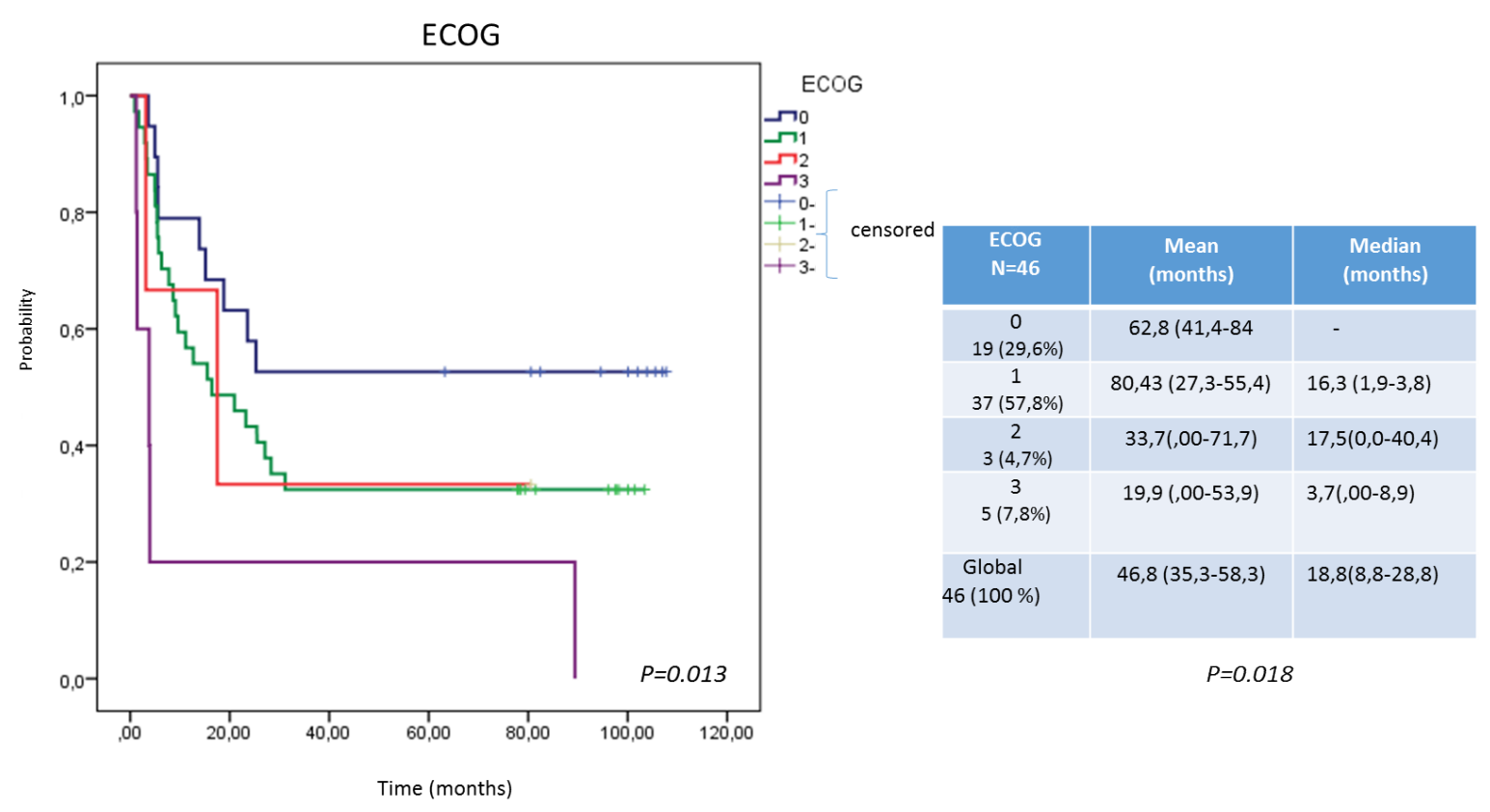

Figure 3: Survival according to ECOG.

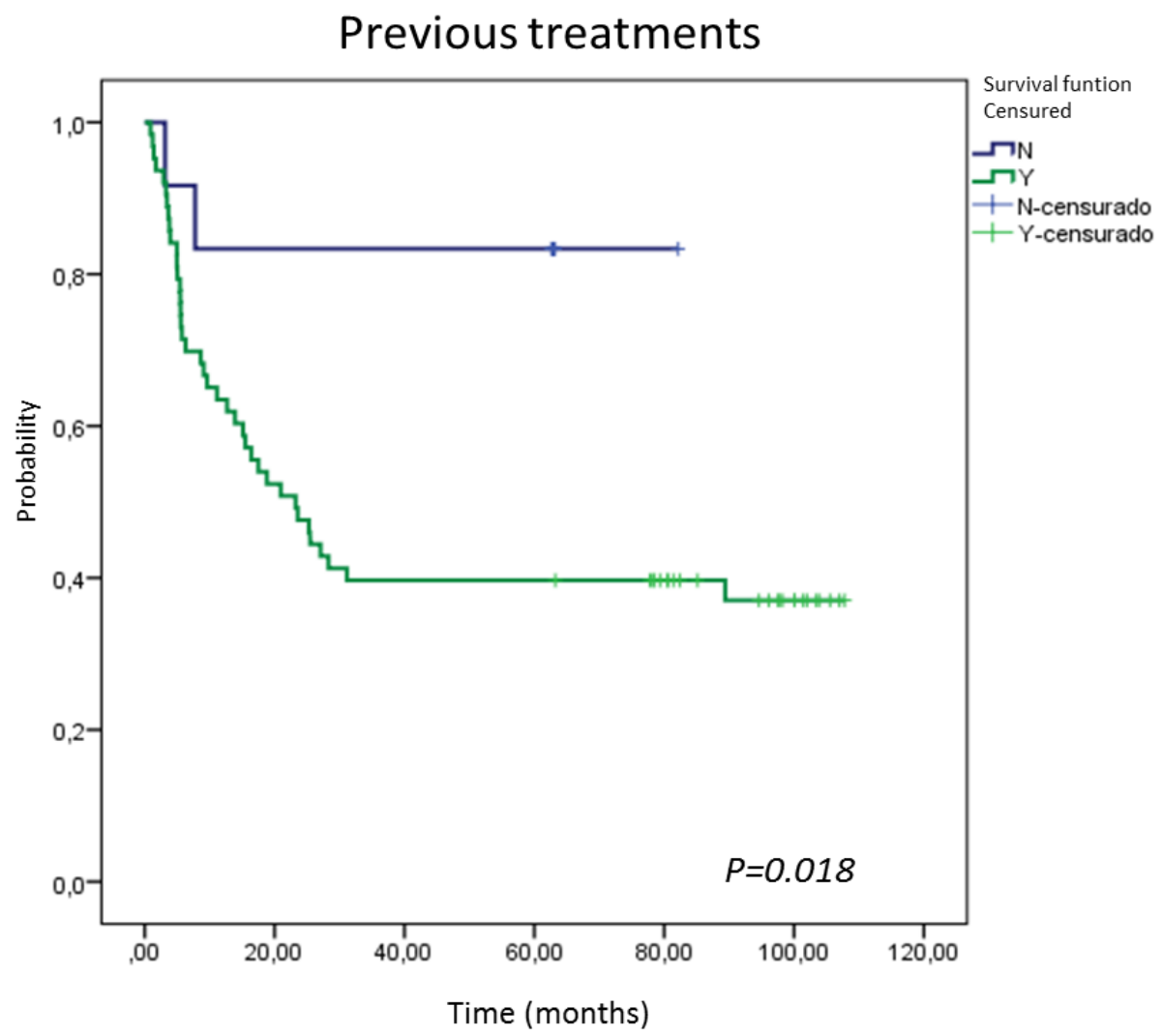

\begin{tabular}{|c|c|c|}
\hline Previous Treatments & $\begin{array}{c}\text { Mean } \\
\text { (months) }\end{array}$ & $\begin{array}{c}\text { Median } \\
\text { (months) }\end{array}$ \\
\hline $\begin{array}{c}\text { No } \\
\mathrm{N}=12(16 \%)\end{array}$ & $69,3(53,1-85,5)$ & Not reach \\
\hline $\begin{array}{c}\text { Yes } \\
\mathrm{N}=63(84 \%)\end{array}$ & $49,0(37,4-60,7)$ & $23,2(13,1-33,3)$ \\
\hline $\begin{array}{c}\text { Global } \\
\mathrm{N}=75(100 \%)\end{array}$ & $55,5(44,6-66,5)$ & $27,0(, 00-89,2)$ \\
\hline
\end{tabular}

Figure 4: Survival according to treatments prior to inclusion in the Expanded Use Program. 
survival [31-34]. Figure 3 shows a lower survival of patients with ECOG 3 with respect to the rest, however, the ECOC 0 (although only 19) have not yet reached the median survival. This may be related to the functional capacity of the patient and the possibility of receiving treatment for a longer time, taking into account that nimotuzumab not only represents a passive therapy concerning receptor blockade and inhibition of its functions, but, is capable of developing a stimulatory effect in the immune system. This Mab in addition is able to induce antibody-dependent cell-mediated cytotoxicity (ADCC) response and apoptosis, involves the activation of the immune system in terms of the adaptive and innate response [33,34].

Figure 4 shows the survival analysis taking into account the patients who received previous therapies in relation to those who arrived at the study in advanced disease without therapeutic option. Independently that the group is unbalanced, those that did not receive previous treatment showed a survival advantage, this could be related to the transformations that the tumor is developing every time that it receives an oncospecific therapy, in relation to the virgin tumors of treatment. Dueñas and cols [34] Reported tumor resistance increase as direct relation to the state of tumor progression because it being expected to acquire additional genetic and epigenetic alterations as it progresses, and this, directly or indirectly, provides protection from the cytotoxic or cytostatic effect of the onco-specific treatments used [33,34]. An additional factor that frequently interferes with the use of chemotherapy is the poor reserve of the bone marrow because of previous pelvic radiotherapy. This also worsened the response to treatments. Coincidentally, patients who did not receive previous treatments had tumors of the squamous cell carcinoma type, which are reported as EGFR over-expressers, so that therapy with an inhibitor should result in a therapeutic benefit $[25,26]$.

\section{Conclusions}

The use of nimotuzumab as biological therapy in patients with cervical cancer in advanced stages proved to be safe and well tolerated. The survival profile obtained in the present study could constitute a therapeutic alternative in this stage of the disease whether persistent, recurrent or metastatic at diagnosis, in which no response has been obtained with the onco-specific treatments established for previous stages. The histological type, the previous treatments and the ECOG could be prognostic factors to the response to this therapy. It is proposed to continue a phase III clinical trial in the same set of patients or in earlier stages of this disease in which one use a nimotuzumab as a therapeutic approach.

\section{References}

1. Gage JC, Schiffman M, Katki HA, Castle PE, Fetterman B, et al. (2014) Reassurance against future risk of precancer and cancer conferred by a negative human papillomavirus test. J Natl Cancer Inst 106

2. Cervical Cancer: Estimated Incidence, Mortality and Prevalence World wide in 2012. International Agency for research on Cancer and World Health Organization

3. Jemal A, Bray F, Center MM, Ferlay J, Ward E, et al. (2011) Global Cancer Statistics. CA Cancer J Clin 61: 69-90.

4. Publicación OPS (2008) Estrategia y Plan de Acción Regionales sobre la Prevención y el Control del Cáncer Cervicouterino.

5. Anuario Estadístico de Salud (2016) MINSAP. Dirección de Registros Médicos y Estadísticos. ISSN, versiónelectrónica 1561-4433. La Habana.

6. Kjaer SK, Frederiksen K, Mun KC, Iftner T (2010) LongTerm absolute risk of cervical intraepithelial neoplasia grade 3 or worse following human papillomavirus infection: role of persistence. J Natl Cancer Inst 102: 1478-1488.

7. Rodríguez AC, Schiffman M, Herrero R, Hildesheim A, Bratti C, et al. (2010) Longitudinal study of human papilloma virus persistance and cervical intraepithelial neoplasia grade 2/3: critical role of duration of infection. J Nalt Cancer Inst 102: 315-324.

8. Parkin DM, Bray F, Ferlay J, Pisani P (2005) Global cancer statistics, 2002. CA Cancer J Clin 55: 74-108.

9. International Collaboration of Epidemiological Studies of Cervical Cancer (2006) Comparison of risk factor for invasive squamous cell carcinoma and adenocarcinoma of the cérvix: collaborative reanalysis of individual data on 8,097 women with squamous cell carcinoma and 1,374 women with adenocarcinoma from 12 epidemiological studies. Int J Cancer 120: 885-891.

10. Dugue PA, Rebolj M, Garred P, Lynge E (2013) Immunosuppression and risk of cervical cáncer. Expert Rev Anticancer Ther 13: 20-42.

11. Manejo Terapéutico del Carcinoma de Cuello Uterino. Consenso de Ginecología FASGO 2017 (Comité de Consenso Federación Argentina de Ginecología y Obstetricia).

12. Steller MA, Delgado CH, Bartels CJ, Woodworth CD, Zou $Z$ (1996) Overexpression of the insulin-like growth factor-1 receptor and autocrine stimulation in human cervical cancer cells. Clin Cancer Res 56: 1761-1765.

13. Biesterfeld S, Schuh S, Muys L, Rath W, Mittermayer C, et al. (1999) Absence of epidermal growth factor receptor expression in squamous cell carcinoma of the uterine cervix is an indicator of limited tumor disease. Oncol Rep 6: $205-209$

14. Kersemaekers AM, Fleuren GJ, Kenter GG, Van den Broek LJ, Uljee SM, et al. (1999) Oncogene alterations in carcinomas of the uterine cervix: Overexpression of the epidermal growth factor receptor is associated with poor prognosis. Clin Cancer Res 5: 577-586.

15. Lage A, Crombet T, González G (2003) Targeting epidermal growth factor receptor signaling: early results and future trends in oncology. Ann Med 35: 327-336.

16. Crombet Ramos T (2014) Nimotuzumab: A Humanized Anti-EGFR Antibody. In: Stefan Dübel, Janice M, Reichert, Handbook of Therapeutic Antibodies.

17. Chen YF, Tang WB, Pan XX, Wu CR, Cao Y, et al. (2017) Safety and efficacy of nimotuzumab combined with chemoradotherapy in Chinese pactients with locally advanced cervical cancer. Onco Targets and Therapy 10: 4113-4119. 
18. Cetina L, Crombet T, Jiménez-Lima R, Zapata S, Ramos M, et al. (2015) Apilot study of nimotuzumab plus single agent chemotherapyas second-or third-line treatment or more in patients with recurrent, persistent or metastatic cervical cáncer. Cancer Bilogy \& Therapy 16: 684-689.

19. Crombet T, Osorio M, Cruz T, Roca C, del Castillo R, et al. (2004) Use of the Humanized Anti-Epidermal Grow Factor Receptor Monoclonal Antibody h-R3 in Combination whith Radiotherapy in the Treatment in Combination whith Radiotherapy in the Treatment of Locally Advance Head and Neck Cancer Patients. Journal of Clinical Oncology 22: 1646-1654.

20. Ramos-Suzarte M, Lorenzo-Luaces $P$, Lazo NG, Perez $\mathrm{ML}$, Soriano JL, et al. (2012) Treatment of malignant, non-resectable, epitelial origin esophageal tumors with the humanized anti-epidermal growth factor antibody nimotuzumab combined with radiation therapy and chemotherapy. Cancer Biology \& Therapy 13: 600-605.

21. Rodríguez MO, Rivero TC, del Castillo Bahi R, Muchuli CR, Bilbao MA, et al. (2010) Nimotuzumab plus radiotherapy for unresectable squamous-cell carcinoma of the head and neck. Cancer Biology \&Therapy 9: 343-349.

22. Tewari KS, Sill MW, Long HJ, Penson RT, Huang $\mathrm{H}$, et al. (2014) Improved survival with bevacizumab in advanced cervical cáncer. N Engl J Med 370: 734-743.

23. Borcoman E, Le Tourneau C (2017) Pembrolizumab in cervical cancer: Lates evidence and clinical usefulness. Therapeutic Advances in Medical Oncology 9: 431-439.

24. Frenel JS, Le Tourneau C, O'Neil B, Ott PA, Piha-Paul SA, et al. (2017) Safety and Efficacy of Pembrolizumab in Advanced, Programmed Death Ligand 1-Positive Cervical Cancer: Results From the Phase Ib KEYNOTE-028 Trial. Journal of Clinical Oncology 36: 4035-4041.

25. Taucher S, Rudas M, Gnant M, Thomanek K, Dubsky $P$, et al. (2003) Sequential steroid hormone receptor measurements in primary breast cancer with and without intervening primary chemotherapy. Endocrine-Related Cancer 10: 91-98.

26. Córdoba A, Ederra M, Ariceta I, Gómez ML, Arrechea MA, et al. (2006) Modulation of biomarkers expression (OR, $\mathrm{PR}$ and $\mathrm{C}$-erbB2) in breast cancer following neoadjuvant treatment. An Sist Sanit Navar 29.

27. Liccardi G, Hartley JA, Hochhauser D (2011) EGFR Nuclear Translocation Modulates DNA Repair following Cisplatin and Ionizing Radiation Treatment. Cancer Res 71: 1-12.

28. Longley DB, Johnston PG (2005) Molecular mechanisms of drug resistance. J Pathol 205: 275-292.

29. National Cancer Institute (2014) FDA approval for Bevacizumab.

30. Lu H, Wu Y, Liu X, Jiang H, Pang Q, et al. (2018) Prospective study on neoadjuvant chemoradiotherapy plus anti-EG FR monoclonal antibody followed by surgery for locally advanced cervical cancer. OncoTargets and Therapy 11: 3785-3792.

31. Blanco R, Cedeño M, Reginfo CE, Blanco D, Frometa M, et al. (2017) Double Expression of Epidermal Grouwth Factor Receptor and N-Glicolil GM3 Ganglioside in Human Malignant Tumors: A Study in Four Different Clinical Scenarios. Advances in Molecular Diagnostics 2: 1-6.

32. Mazorra Z, Lavastida A, Concha-Benavente F, Valdés A, Srivastava RM, et al. (2017) Nimotuzumab Induces NK CellActivation, Cytotoxicity, Dendritic Cell Maturation and Expansion of EGFR-Specific T Cells in Head and Neck Cancer Patients. Frontiers in Pharmacology 8.

33. Mazorra Z, Chao L, Lavastida A, Sanchez B, Ramos M, et al. (2018) Nimotuzumab: Beyond the EGFR signaling cascade inhibition. Seminars in Oncology.

34. Dueñas-González A, Cetina L, Coronel J, Martínez-Baños D (2010) Pharmacotherapy Options for Locally Advanced and Advanced Cervical Cancer. Drugs 70: 403-432. 